\title{
Co-existence of wind seas and swells along the west coast of India during non-monsoon season
}

\author{
R. Rashmi ${ }^{1}$, V. M. Aboobacker ${ }^{2}$, P. Vethamony ${ }^{1}$, and M. P. John ${ }^{3}$ \\ ${ }^{1}$ National Institute of Oceanography (CSIR), Dona Paula, Goa, India \\ ${ }^{2}$ Tropical Marine Science Institute, National University of Singapore, Singapore \\ ${ }^{3}$ National Institute of Ocean Technology, Chennai, India \\ Correspondence to: R. Rashmi (rshray7@gmail.com) \\ Received: 5 September 2012 - Published in Ocean Sci. Discuss.: 4 October 2012 \\ Revised: 31 January 2013 - Accepted: 19 February 2013 - Published: 8 March 2013
}

\begin{abstract}
An attempt has been made to understand the coexistence of wind seas and swells along the west coast of India during non-monsoon season. Wave data were collected in different years during non-monsoon season (off Goa during May 2005, off Ratnagiri during January-February 2008 and off Dwarka during December 2007-January 2008), which is fairly a calm weather season along these regions. Diurnal variation in wave parameters is noticeable along the central west coast of India (off Goa and Ratnagiri), which is due to the interaction of multidirectional waves (both wind seas and swells) of varying magnitudes and frequencies. Swells are predominantly mature $(91 \%)$ and old $(88 \%)$ during late pre-monsoon and post-monsoon seasons, respectively. Sea Swell Energy Ratio quantifies wind sea, swell and mixed seas prevailing in these regions during non-monsoon season. Intermodal distance (ID) between the energy peaks is moderately separated during non-monsoon season, whereas, during the shamal events, energy peaks are very close to each other (ID $\sim 0$ ). However, pure wind seas (ID $\sim 1$ ) are weakly present and found to co-exist with the swells almost all the time during non-monsoon season. Wind sea growth has been found while the swell propagates opposite to the direction of the wind and wind sea. Wind seas have minimum angular spreads in multimodal state. Under low winds, the interaction between wind sea and swell dominates and thereby the multimodal state reduces to unimodal state. The fetch available for the evolution of the wind sea spectrum has been estimated, and it is found to be less than $150 \mathrm{~km}$. For the fetch limited condition, a non-dimensional empirical relation has been derived relating the significant wind sea height in terms of wind speed and peak wind sea period, and this relation fits for the west coast of India.
\end{abstract}

\section{Introduction}

Ocean wave spectra consist of wind seas generated by local winds and swells of distant storms. The characteristics of these waves are different in different seasons (Alves, 2006; Semedo et al., 2011). An attempt has been made to understand the co-existence of wind seas and swells at different coastal regions in the Indian side of the Arabian Sea during non-monsoon season. Wave spectra along the west coast of India are generally multi-peaked (Harish and Baba, 1986; Kumar et al., 2003; Sanil Kumar et al., 2007), and multipeakedness is mainly due to the co-existence of locally generated wind seas and distant swells (Vethamony and Sastry, 1986). It has been observed that winds along the west coast of India are primarily dominated by sea breeze-land breeze systems during pre-monsoon season (Aparna et al., 2005). Sea breeze has impact on the diurnal cycle of sea state off Goa (Neetu et al., 2006), and the diurnal variations are due to the superimposition of local wind seas with pre-existing swells (Vethamony et al., 2009, 2011). The development of pure wind-driven waves is controlled by three basic processes: energy input from wind to surface waves, nonlinear wave-wave energy transfer and energy dissipation due to wave breaking. The interaction of individual wave systems in the directional and frequency spaces is an important factor in how the coexistence of swells modify the growth of wind driven waves.

Identification and separation of wave components into wind seas and swells provide a more realistic description of the sea state, and this has importance to both scientific and engineering applications. Gerling (1992) identified and grouped wave systems from spatially and temporally 
distributed observations of directional wave spectra. Hanson and Phillips (2001) developed automated swell tracking and storm source identification capabilities to facilitate investigations of surface wave processes in the open ocean. Based on wave steepness, Gilhousen and Hervey (2001) and Wang and Hwang (2001) estimated separation frequency to distinguish wind sea and swell. Portilla et al. (2009) found that the use of partitioning gives more consistent identification results for both 1-D and 2-D spectra. They improved the results of wind sea and swell classification from 1-D spectra by proposing an algorithm for peak enhancement factor $\left(\gamma^{*}\right)$. The available partitioning methods (e.g. Gerling, 1992; Wang and Hwang, 2001; Portilla et al., 2009) primarily involve separating the wave spectra into two frequency bands, low-frequency band representing swells and a high-frequency band representing wind seas. However, multidirectional peaks within the divided spectrum (swell or wind sea part) are usually merged, irrespective of the direction of each peak. The distinction between wind sea and swell is often not obvious. Under changing winds (both magnitude and direction) wave systems can overlap in the frequency-direction domain, giving origin to a rather continuous spectrum in which the presence of two or more distinct systems is not clearly discernible. Wave systems in these situations are referred to as mixed sea states and are particularly difficult to detect and/or identify by automated procedures (Portilla et al., 2009). We have done the sensitivity test for the partitioning methods (Aboobacker et al., 2011b) and found Gilhousen and Hervey (2001) method was suitable for the west coast of India.

As sea state develops, due to nonlinear interactions peak energy shifts towards lower frequencies. Distinct double peaks in the spectra indicate that wind sea and swell energies are well separated. Relatively close double peaks (looks as if single-peaked) indicate a combination of two wave systems coming from the same/different directions (Guedes Soares, 1991). Guedes Soares (1984) proposed the ratio of peak frequencies of two components to describe the relation between two wave systems. Rodriguez and Guedes Soares (1999) proposed two related parameters, the Sea Swell Energy Ratio (SSER) and the intermodal distance (ID) for the classification of sea states and to identify spectral distribution in each sea state. In the present study, the asymmetric and bimodal nature of spectral distribution is examined for these two parameters.

Recently, there has been a renewed interest in studying the swell characteristics. Alves (2006) studied the generation, propagation and attenuation of swells globally, whereas Semedo et al. (2011) presented the detailed global climatology, based on ERA-40, of wind sea and swell characteristics. Aboobacker et al. (2011b) have identified potential swell generation areas during different seasons in the Arabian Sea (from SW direction during SW monsoon and from SW/SSW and NW directions during both pre-monsoon and post-monsoon seasons). It has been shown that swell decay rates have an impact on the marine atmospheric boundary layer (MABL) and are related to a reverse momentum flux process. In order to know the types of swells prevailing in the Arabian Sea during non-monsoon seasons, we have classified swells into young, mature and old swells based on significant wave steepness - a measure of relative wave age (Thompson et al., 1984). Swell steepness diminishes as it propagates into distant areas. Swells having steepness value less than 0.004 are considered as old swell, between 0.010 and 0.004 as mature swells and between 0.025 and 0.010 as young swells.

Holthuijsen (1983) found that shape of the directional energy distribution in a non-ideal situations it strongly influences the geometry of the fetch. Donelan et al. (1985) also found that the fetch geometry plays a significant role in wave development. Ardhuin et al. (2007) considered two situations: an ideal fetch-limited wave generation and a nonideal situation which includes slanted fetch. For moderate angles between the wind and shore-normal direction (i.e. slanting fetch) and for unstable atmospheric condition, Ardhuin et al. (2007) observed that evolution of nondimensional parameters agree well with growth curves obtained by Kahma (1981). Kahma (1981) studied development of wave spectrum with fetch in a steady wind using wave buoy data in the Bothnian Sea and found a relation between dimensionless peak frequency and dimensionless fetch.

In the present study, we have separated the wave directional spectrum into wind seas and swells to examine how the wind sea growth modifies in the presence of pre-existing swells during non-monsoon season for different years at three locations along the west coast of India. Further, fetch estimation for wind sea generation has been done. A nondimensional empirical relationship has been derived for the wind seas generated along the west coast of India during premonsoon and post-monsoon seasons.

\section{Area of study}

The study area and measurement locations are shown in Fig. 1. Goa and Ratnagiri are located on the central west coast of India, separated by a distance of $185 \mathrm{~km}$. The topographic features are nearly the same and the bathymetry contours are almost parallel to the coast. The shorelines of Goa and Ratnagiri are oriented at $337.5^{\circ}$ and $348.75^{\circ}$, respectively with respect to the north. Dwarka is situated along the northwest coast of India, and the shoreline is oriented at $315^{\circ}(\mathrm{NW})$ with respect to the north. The northern part of Dwarka is open to the Gulf of Kachchh, a semienclosed basin. Off Dwarka, the bathymetry is irregular and very complex (Fig. 1).

The west coast of India, in general, experiences three types of seasons: pre-monsoon (February-May), southwest monsoon (June-September) and post-monsoon (OctoberJanuary). Waves are usually very high during SW monsoon season and the predominant swells are from SW/WSW. During non-monsoon season (post- and pre-monsoons), along 
Table 1a. Details of wave data.

\begin{tabular}{lrrrl}
\hline Location & Latitude $\left({ }^{\circ} \mathrm{N}\right)$ & Longitude $\left({ }^{\circ} \mathrm{E}\right)$ & Water depth $(\mathrm{m})$ & \multicolumn{1}{l}{ Duration } \\
\hline Goa (late pre-monsoon) & $15^{\circ} 29^{\prime} 18^{\prime \prime}$ & $73^{\circ} 42^{\prime} 1.2^{\prime \prime}$ & 25 & 1-21 May 2005 \\
(May 2005) & $15^{\circ} 25^{\prime} 24^{\prime \prime}$ & $73^{\circ} 44^{\prime} 55^{\prime \prime}$ & 15 & 6-21 May 2005 \\
Ratnagiri (early pre-monsoon) & $17^{\circ} 00^{\prime} 15.1^{\prime \prime}$ & $73^{\circ} 07^{\prime} 17.3^{\prime \prime}$ & 35 & 24 Jan-25 Feb 2008 \\
(Jan-Feb 2008) & $17^{\circ} 00^{\prime} 25.4^{\prime \prime}$ & $73^{\circ} 15^{\prime} 00.7^{\prime \prime}$ & 15 & 24 Jan-25 Feb 2008 \\
Dwarka (post-monsoon) & $22^{\circ} 05^{\prime} 15.7^{\prime \prime}$ & $69^{\circ} 01^{\prime} 8.24^{\prime \prime}$ & 30 & 3 Dec 2007-6 Jan 2008 \\
(Dec 2007-Jan 2008) & $22^{\circ} 04^{\prime} 7.85^{\prime \prime}$ & $69^{\circ} 05^{\prime} 24.0^{\prime \prime}$ & 15 & 3 Dec 2007-6 Jan 2008 \\
\hline
\end{tabular}

Table 1b. Details of AWS wind measurements.

\begin{tabular}{lrrc}
\hline Location & Latitude $\left({ }^{\circ} \mathrm{N}\right)$ & Longitude $\left({ }^{\circ} \mathrm{E}\right)$ & $\begin{array}{c}\text { Distance between the buoy } \\
\text { and AWS locations (km) }\end{array}$ \\
\hline $\begin{array}{l}\text { Goa (late pre-monsoon) } \\
\text { (May 2005) }\end{array}$ & $15^{\circ} 27^{\prime} 20.02^{\prime \prime}$ & $73^{\circ} 48^{\prime} 8.44^{\prime \prime}$ & 7 \\
$\begin{array}{l}\text { Ratnagiri (early pre-monsoon) } \\
\text { (Jan-Feb 2008) }\end{array}$ & $16^{\circ} 53^{\prime} 35^{\prime \prime}$ & $73^{\circ} 16^{\prime} 55^{\prime \prime}$ & 13 \\
$\begin{array}{l}\text { Dwarka (post-monsoon) } \\
\text { (Dec 2007-Jan 2008) }\end{array}$ & $68^{\circ} 57^{\prime} 59.21^{\prime \prime}$ & $22^{\circ} 14^{\prime} 32.92^{\prime \prime}$ & 23 \\
\hline
\end{tabular}

with predominant swells from SW/SSW, shamal swells (NW swells) are also present. Shamal swells (NW swells) (Aboobacker et al., 2011a) are generated in the NW Arabian Sea due to strong shamal winds during winter shamal events (November-March), which occur during post-monsoon and early pre-monsoon seasons. They propagate in the Arabian Sea influencing the west coast of India significantly. The vertical lines from 1 to 6 in Figs. 2 and 4 refer to shamal events as the wind and wave characteristics exhibit distinct features such as, increase in wave height associated with decrease in swell period and a common propagation direction (NW) for wind, wind sea, swell and resultant waves. During this period, $\mathrm{Hs}$ are in the range of 1.0 to $2.0 \mathrm{~m}$, and mean swell periods are between 6.0 and $8.0 \mathrm{~s}$.

\section{Data and methodology}

Wave data have been collected at 6 locations (Fig. 1) off Goa, Ratnagiri and Dwarka using Datawell Directional Waverider Buoys (Datawell, B.V., 2006). Table 1a provides details of geographical location, water depth and wave measurement duration. Data have been recorded for $20 \mathrm{~min}$ duration at $30 \mathrm{~min}$ interval. Simultaneous wind measurements at $10 \mathrm{~min}$ sampling intervals were carried out using Autonomous Weather Station (AWS) installed near the coast (accuracy of AWS: $\pm 0.3 \mathrm{~m} \mathrm{~s}^{-1}$ for wind speed and $\pm 3^{\circ}$ for wind direction). The details (position and distance to the wave rider buoys) of AWS data are given in the Table 1b; the data were reduced to $10 \mathrm{~m}$ height, using Prandtl 1/7 law approximation (Peterson and Hennessey, 1978). Further, we have also used CERSAT / IFREMER Blended winds (Bentamy et al., 2006) available in $0.25^{\circ} \times 0.25^{\circ}$ grids at $6 \mathrm{~h}$ in- tervals in the form of $U$ (zonal) and $V$ (meridional) components.

Wind sea and swell parameters have been separated from the wave spectra using the methodology proposed by Gilhousen and Hervey (2001). The separation is based on the wave steepness algorithm, which partitions the wave spectrum into wind sea and swell components. The steepness parameter (ratio between wave height and wavelength) of each frequency is calculated to estimate the separation frequency. The wave steepness parameter, $\xi$ at all frequencies $f$, can be written as

$\xi(f)=\frac{8 \pi \int_{f_{1}}^{f_{\mathrm{u}}} f^{2} E(f) \mathrm{d} f}{g \sqrt{\int_{f_{1}}^{f_{\mathrm{u}}} E(f) \mathrm{d} f}}$.

Where, $f_{\mathrm{u}}=$ upper frequency limit $(0.58), f_{1}=$ lower frequency limit and it varies as $f_{1}=0.025,0.03,0.035, \ldots$, 0.58. $E(f)=$ variance density and $g=$ acceleration due to gravity. $\xi(f)$ for all frequencies has been calculated from the measured data. The peak frequency $f_{x}$ of the steepness parameter $\xi(f)$ has been identified, and then used to calculate the separation frequency $f_{\mathrm{s}}$ as follows:

$f_{\mathrm{s}}=C f_{x}$

where $C=0.75$ is an empirically determined constant (Gilhousen and Hervey, 2001). The wind sea and swell part of the spectra have been separated using $f_{\mathrm{s}}$, and accordingly, significant wave height, mean wave period and mean wave direction of wind seas and swells were calculated from the moments.

The swell part of the spectrum is classified as young, mature and old swells based on significant wave steepness 

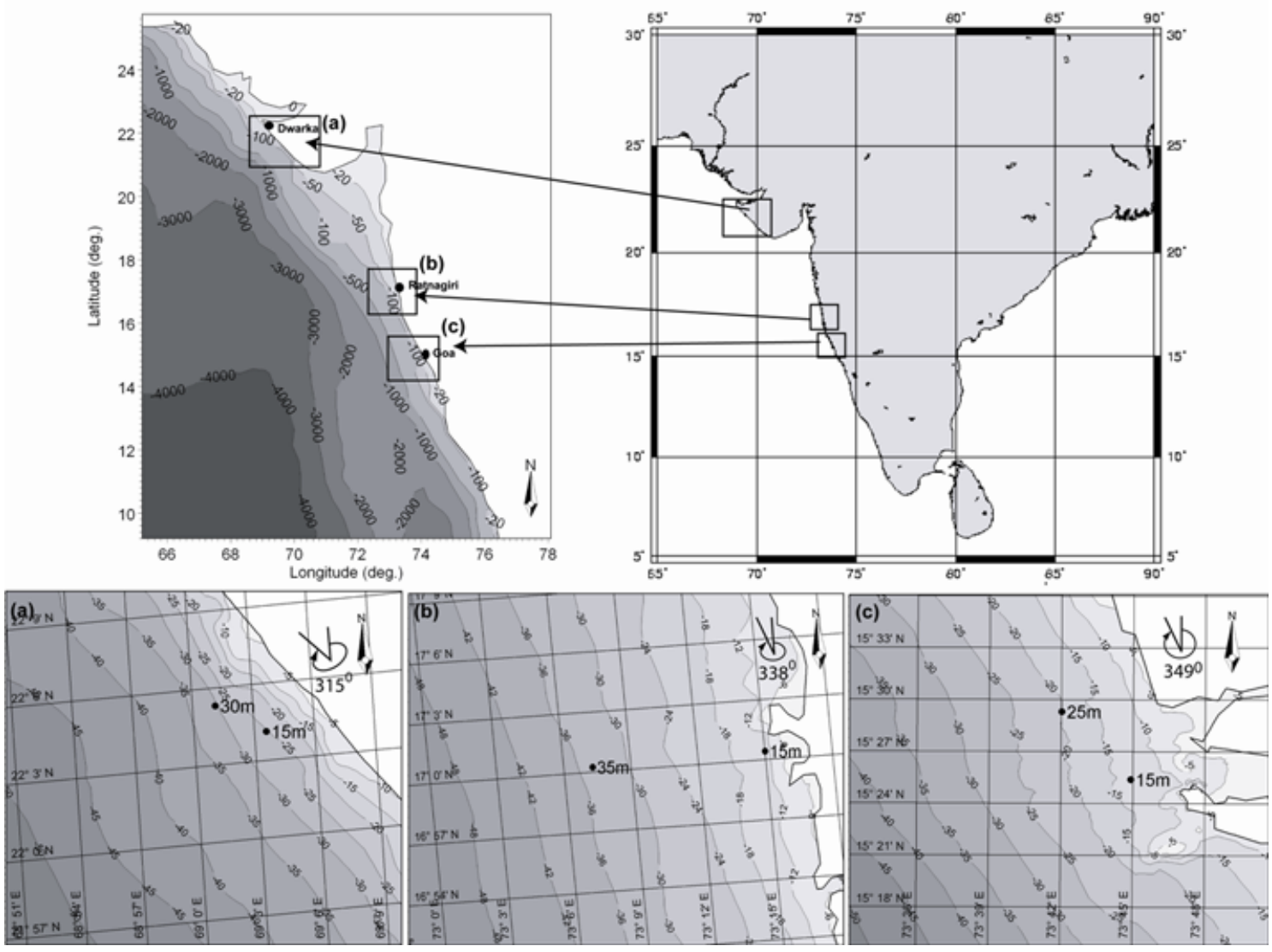

Fig. 1. Wave measurement location and its bathymetry contours along the west coast of India. Angles mentioned in the figures are the orientation of the coastline w.r.t the north.

(Thompson et al., 1984), which is defined as the ratio between significant wave height and wavelength $\left(\frac{H_{\mathrm{s}}}{\lambda}\right)$. The sea states along the west coast of India are classified according to the dimensionless parameters, SSER and ID (Rodriguez and Guedes Soares, 1999).

SSER is the ratio of energies associated with each wave system as given below:

$\operatorname{SSER}=\left(\frac{m_{0 \mathrm{ws}}}{m_{0 \mathrm{sw}}}\right)$

where $m_{0 \mathrm{ws}}$ is the zero order moment of wind sea and $m_{0 \mathrm{sw}}$ the zero order moment of swell part of the spectrum. These are calculated based on spectral moment $m_{0}$, defined as

$m_{0}=\int_{0}^{\infty} S(f) \mathrm{d} f$.

The sea states are classified as follows: (i) swell dominated sea state $(\mathrm{SSER} \leq 0.8)$ : the major part of the wave energy is associated with low frequency spectral peak, (ii) mixed sea state with comparable energy of wind sea and swell $(0.8<$ SSER $<1.2)$ : the wave energy is distributed over the low and high frequency ranges and (iii) wind sea dominated sea state (SSER $\geq 1.2$ ): the maximum energy is confined to high frequency part of the spectrum.

Intermodal distance (ID) is the frequency separation between the spectral frequency peaks, $f_{\mathrm{p}}$, corresponding to swell and wind sea, which is defined as:

$\mathrm{ID}=\left(\frac{f_{\mathrm{pws}}-f_{\mathrm{psw}}}{f_{\mathrm{pws}}+f_{\mathrm{psw}}}\right)$,

where $f_{\mathrm{pws}}$ is the peak frequency of wind sea and $f_{\mathrm{psw}}$ is the peak frequency of swell part of spectra.

The dominant sea states are classified based on ID as follows: (i) ID value close to zero, that is, when swell and wind sea spectral peaks are very close to each other; (ii) wave fields with double-peaked sea states whose modal spectral frequencies are moderately separated; and (iii) ID close to 1.0, which represents sea state with swell and wind sea spectral peaks well separated. We have selected the range for each class of ID as follows: (i) ID-I (ID $\leq 0.3$ ), (ii) ID-II $(0.3<$ ID $<0.7)$, and (iii) ID-III (ID $\geq 0.7)$. Depending on swell or wind sea absence, ID may vary from 0 (pure swell) to 1 (pure wind sea).

As the situation described in Ardhuin et al. (2007), i.e. moderate angles between the wind and shore-normal 

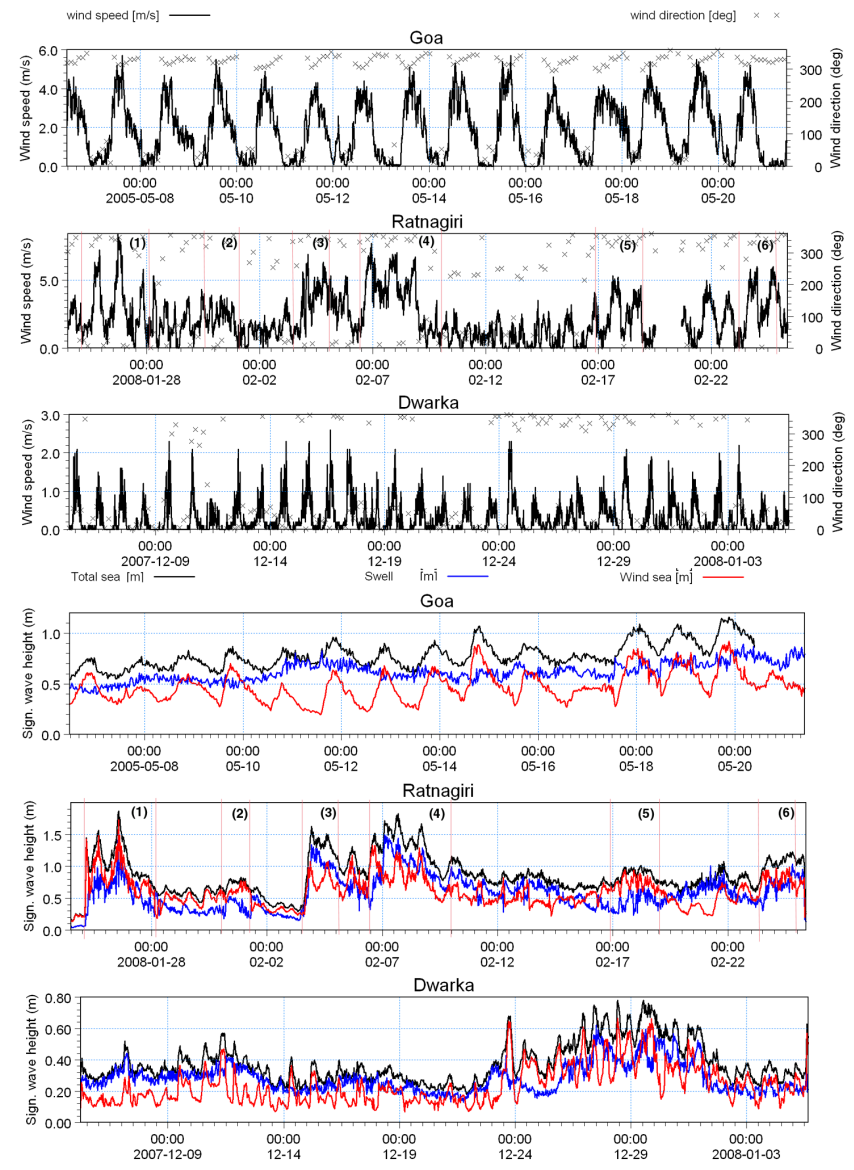

Fig. 2. Wind parameters (wind speed and direction) and significant wave height (total sea - black, swell - blue and wind sea - red) off Goa, Ratnagiri and Dwarka. Vertical lines from 1 to 6 in wind and wave parameters off Ratnagiri are related to shamal events.

direction (i.e. slanting fetch) and unstable atmospheric condition, fits for the west coast of India; we have used the equation obtained by Kahma (1981) for the estimation of fetch for wind sea generation.

A non-dimensional empirical relationship has been derived based on wind (blended winds) and wind sea parameters estimation of the non-dimensional significant wind sea height $H_{\mathrm{Sws}}^{*}$ and non-dimensional peak wind sea period $T_{\mathrm{Pws}}^{*}$ as follows:

$H_{\mathrm{Sws}}^{*}=\frac{g H_{\mathrm{ws}}}{U^{2}} a n d T_{\mathrm{Pws}}^{*}=\frac{g T_{\mathrm{Pws}}}{U}$,

where $g=$ acceleration due to gravity, $U=$ wind speed $\left(\mathrm{ms}^{-1}\right)$ at $10 \mathrm{~m}$ height, $H_{\text {Sws }}=$ significant wind sea height (m), and $T_{\mathrm{Pws}}=$ peak wind sea period (s).

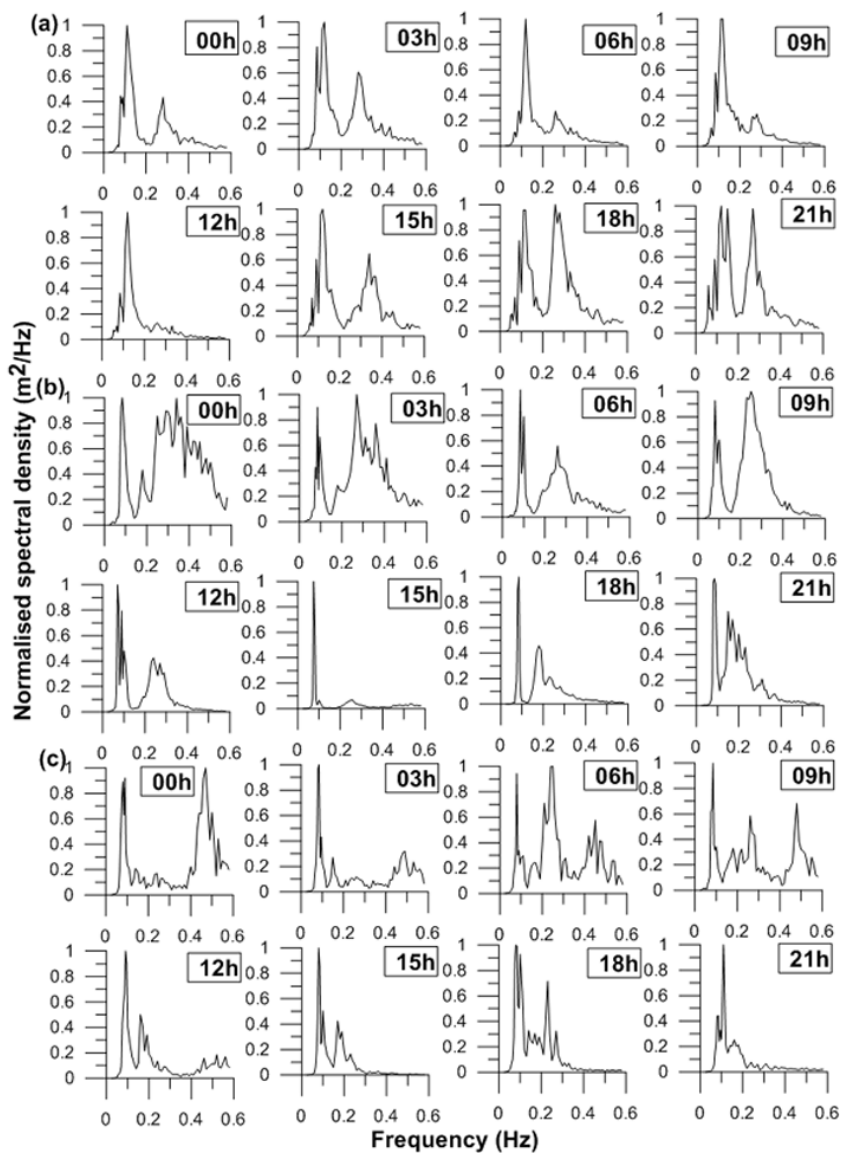

Fig. 3. Typical 1-D spectra measured off (a) Goa during 9 May 2005, (b) Ratnagiri during 3 February 2008 and (c) Dwarka during 22 December 2007.

\section{Results and discussion}

\subsection{Diurnal variability}

Variations of coastal winds and significant wave heights, wind seas and swells off Goa, Ratnagiri and Dwarka, at 25, 35 and $30 \mathrm{~m}$ water depth, respectively, are presented in Fig. 2. Local winds play a major role in shaping the wave characteristics along the west coast of India. For example, it has been observed earlier that winds and waves along the west coast of India exhibit systematic diurnal variations during pre-monsoon season (Vethamony et al., 2011) and predominant winds are either from NW (sea breeze) or NE (land breeze). Winds from NE are generally weak, and it extends only a few kilometers from the coast, whereas the NW winds are strong, especially in the afternoon hours. The wind seas generated under fetch-limited conditions interact with the swells arriving from SW. The mean periods of these swells are between 6 and $11 \mathrm{~s}$ and the wind seas are between 2 and $4 \mathrm{~s}$. Diurnal variations are present during early pre-monsoon and post-monsoon seasons as well, but not as significant as pre-monsoon season (Fig. 3). During early pre-monsoon, the 
Table 2. Percentage of swell, wind sea and mixed sea with comparable energy during non-monsoon season.

\begin{tabular}{lrrrrr}
\hline Location & Water depth & No. of & \multicolumn{2}{c}{ Dominance (\%) } \\
\cline { 5 - 6 } & $(\mathrm{m})$ & Observations & Swell & Wind sea & $\begin{array}{r}\text { Mixed sea with } \\
\text { comparable energy }\end{array}$ \\
\hline Goa & 25 & 463 & 54 & 20 & 26 \\
(May 2005) & 15 & 717 & 71 & 11 & 19 \\
Ratnagiri & 35 & 1524 & 39 & 44 & 17 \\
(Jan-Feb 2008) & 15 & 1523 & 39 & 48 & 14 \\
Dwarka & 30 & 1485 & 38 & 45 & 17 \\
(Dec 2007-Jan 2008) & 15 & 1483 & 61 & 24 & 15 \\
\hline
\end{tabular}

predominant winds are from NW and NE. Swells (SW/SSW) are relatively weaker during non-monsoon season; however, the shamal winds generate high NW swells in the Arabian Sea during early pre-monsoon season (Aboobacker et al., 2011a). During post-monsoon season, the predominant winds are from N, NE and NW directions. Systematic diurnal variations are more predominant in pre-monsoon season than the post-monsoon season. The coastal winds off Dwarka show diurnal variations in wind speed and direction, but the diurnal pattern of the waves is not as distinct as off Goa during pre-monsoon season. Due to the interaction of multidirectional wind seas of varying magnitudes in the frequency domain with co-existence of swells during post-monsoon and early pre-monsoon seasons, we do not find systematic diurnal variability both in wave height and wave period, i.e. increase in wave height and decrease in wave period with increase in wind speed.

\subsection{Relative importance between swells and wind seas}

Generally waves are classified into wind sea and swell, when information on mixed sea state is not available. SSER provides detailed analysis of wave systems, classifying them into swell, mixed and wind sea. During late pre-monsoon season, swells are dominant $(54 \%$ and $71 \%$ at $25 \mathrm{~m}$ and $15 \mathrm{~m}$ water depths off Goa, respectively) (Table 2 and Fig. 4). During early pre-monsoon season, waves are primarily dominated by wind seas (44\% and $48 \%$ at $35 \mathrm{~m}$ and $15 \mathrm{~m}$ depths, respectively, off Ratnagiri) followed by swells (39\% at both the depths). However, during post-monsoon season, wind seas are dominant $(45 \%)$ at $30 \mathrm{~m}$ depth (away from the coast) while swells are dominant $(61 \%)$ at $15 \mathrm{~m}$ depth (closer to the coast) off Dwarka. This is attributed to generation of NE wind seas, and their growth is towards offshore. Sufficient fetch is available at $30 \mathrm{~m}$ depth for $\mathrm{NE}$ wind seas to grow compared to $15 \mathrm{~m}$ depth, and hence, wind sea energy is relatively higher at this location. Also it is found that wind seas increase offshore as available fetch increases, whereas swells increase towards the coast due to nonlinear wave-wave interaction and the prevailing wind direction during the study period, and this presents two well defined opposing wave systems. Considerable amount of mixed seas was observed during late pre-monsoon season, whereas, during early premonsoon and post monsoon seasons it was the least. When swells dominate, mixed sea is less, and this happens at the fully developed stage. However, when wind seas dominate, mixed seas also increase as the waves are still in the developing stage. Off Goa and Dwarka, swell height increases as the water depth decreases; on the contrary, wind-sea increases with water depth. Whereas off Ratnagiri, this behavior is not found because the interaction between the multidirectional swells from SW and NW are almost perpendicular to each other. Due to the interaction of these multidirectional swells, swells are decreasing and wind seas are increasing towards the coast. This behaviour is independent of number of peaks present in the spectrum.

In addition to SSER, ID also provides differentiation of the spectral peaks for non-monsoon season. During late premonsoon season, maximum waves are under the category IDII $(85 \%$ and $95 \%$ at $25 \mathrm{~m}$ and $15 \mathrm{~m}$ depths off Goa, respectively, Table 3 ). This indicates that spectral peaks of wind sea and swell are moderately separated. During early premonsoon season, the majority of waves fall under the category ID-I (57\% and $56 \%$ at $35 \mathrm{~m}$ and $15 \mathrm{~m}$ depths off Ratnagiri, respectively), indicating that the spectral peaks are very closer to each other (spectra appear to be unimodal). One example is, the spectral peaks during shamal events (purely swell, ID $\sim 0$ ). During post-monsoon season, all the waves fall under the category ID-II $(60 \%$ and $75 \%$ at $30 \mathrm{~m}$ and $15 \mathrm{~m}$ water depths off Dwarka, respectively), indicating that spectral peaks are moderately separated. Even though wind seas play a dominant role during non-monsoon season, spectrum with pure wind seas (ID 1) was weakly present. The wind sea spectrum was always co-existent with swells, which are prevailing almost all the time.

\subsection{Wave directionality}

The directionality of the wind sea and swell systems is found to influence the development of wind waves. The directional spread distribution of mixed seas exhibits features different from those of pure wind seas. Such mixed seas of swell and 


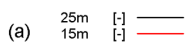

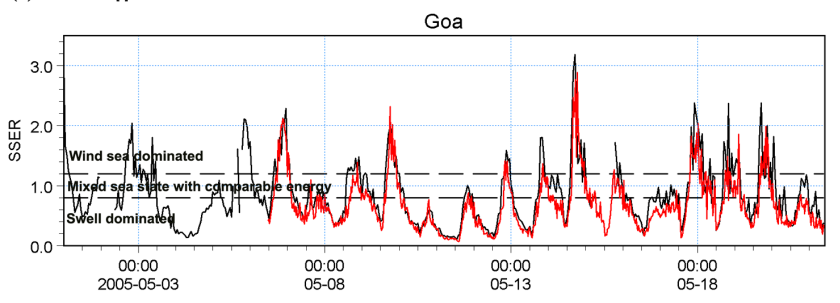

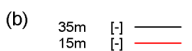

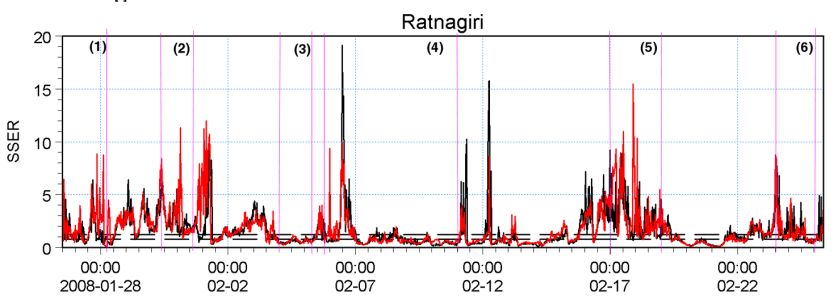

(c) ${ }_{15 m}^{30 m} \stackrel{H}{\mathrm{H}-1}_{\mathrm{H}-\mathrm{C}}=$

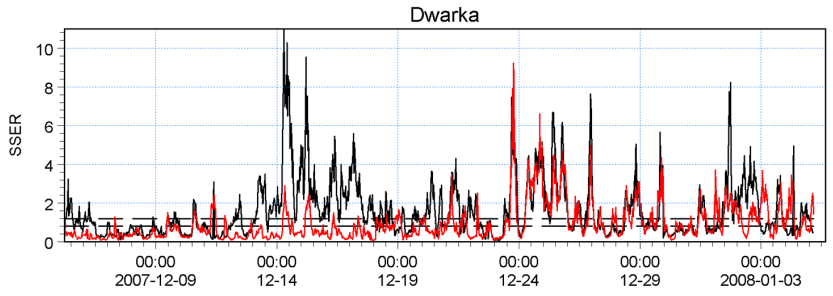

Fig. 4. SSER of wind sea, mixed sea and swell: (a) $15 \mathrm{~m}$ and $25 \mathrm{~m}$ depths off Goa, (b) $15 \mathrm{~m}$ and $35 \mathrm{~m}$ depths off Ratnagiri; vertical lines from 1 to 6 refer to shamal events, and (c) $15 \mathrm{~m}$ and $30 \mathrm{~m}$ depths off Dwarka.

wind seas result in a multimodal wave field, and the development of this multi-system is to be explored.

The minimal directional spread is located at the peak frequency of the spectra. Off Goa, during late pre-monsoon season, we find that wind seas grow when the wind and the wind sea are in the same direction (i.e. both are from NW). During the growth of wind seas, the directional spread ranges between $30^{\circ}$ and $50^{\circ}$. As the wind direction changes from NW to $\mathrm{NE}$ and wind speed reduces (say, $0.5 \mathrm{~m} \mathrm{~s}^{-1}$ ), swells dominate from SW and accelerate the decay of NW wind seas (Fig. 5b). That is, swell and wind sea are nearly normal to each other, whereas, wind is opposite to swell and normal to wind sea direction. At this stage, the bimodal sea state turns into unimodal state (Fig. 5c). The angular spread increases in the higher frequency range above $0.2 \mathrm{~Hz}$ due to the decay of wind seas. As a result of sea breeze at noon hours, wind direction changes from NE to NW, and the speed reaches to a maximum of $5 \mathrm{~m} \mathrm{~s}^{-1}$. Wind sea starts developing and reaches its peak during evening hours with the co-existence of swells from SW direction, leading to a bimodal sea state. As the wind sea matures, the minimal spread of wave energy decreases and shifts towards lower frequency (Fig. 5d).

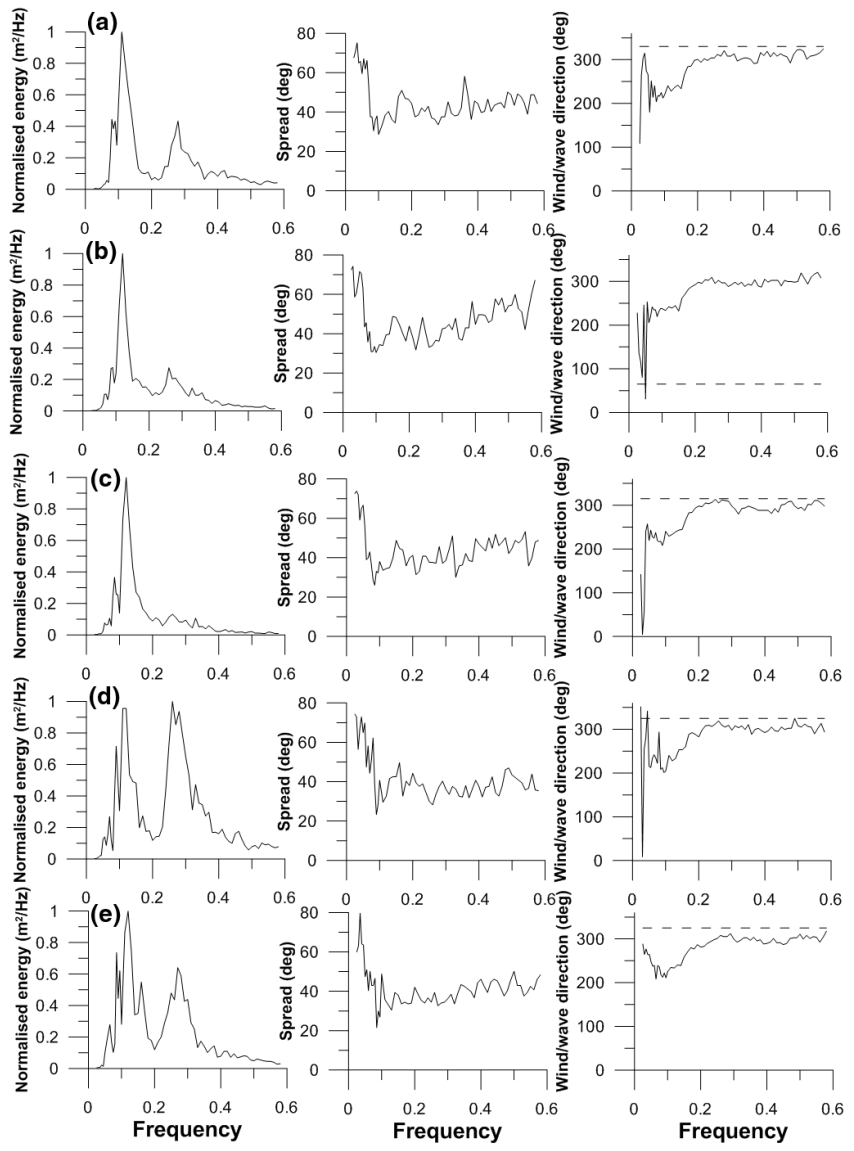

Fig. 5. Wave energy spectrum, wave spread and mean wave direction (solid line) and wind direction (dashed line) at (a) 00:00 h, (b) 06:00 h, (c) 12:00 h, (d) 18:00 h and (e) 23:00 h, respectively, off Goa during 9 May 2005.

Off Ratnagiri, during early pre-monsoon season, we can see four peaks in the spectrum from different directions (Fig. 6a). These peaks are swell from SW and wind sea from SW, NW and NE directions. The contributions of SW and NE wind seas are minimum in the multimodal spectra (Fig. 6a). The angular spread is minimum for wind seas than for swells, with energies distributed over the frequency range 0.2 to $0.4 \mathrm{~Hz}$. The interaction between wind seas and the swells occurs in transforming the young wind seas to mature wind seas. As the wind sea matures, directional spread shifts towards lower frequencies (Fig. 6b). Multimodalism is reduced to bimodalism in the wave spectrum. When the shamal event occurs, the wind and wave directions shift to NW and wind speed reaches to a maximum of $7 \mathrm{~m} \mathrm{~s}^{-1}$. The spectral energy is narrowed down in the swell part of the spectrum in the NW direction (Fig. 6c). Light swell energy from the SW direction is also observed in the wave spectrum with large directional spread. Prevailing swell dominates, and ultimately absorbs the wind sea energy (Fig. 6e). This leads to broadening of energy density of swell peak and to the disappearance of the bimodal state. 
Table 3. Percentage of intermodal distance (ID) along the west coast of India.

\begin{tabular}{lrrrrr}
\hline Location & $\begin{array}{r}\text { Water depth } \\
(\mathrm{m})\end{array}$ & $\begin{array}{r}\text { No. of } \\
\text { observations }\end{array}$ & \multicolumn{3}{c}{$\begin{array}{c}\text { Mean ID values } \\
\text { (observations in \%) }\end{array}$} \\
\cline { 4 - 6 } & & & ID-I & ID-II & ID-III \\
\hline Goa & 25 & 463 & $0.28(14)$ & $0.54(85)$ & $0.72(1)$ \\
(May 2005) & 15 & 717 & $0.28(4)$ & $0.54(95)$ & $0.72(1)$ \\
Ratnagiri & 35 & 1524 & $0.1(57)$ & $0.55(40)$ & $0.71(3)$ \\
(Jan-Feb 2008) & 15 & 1523 & $0.1(56)$ & $0.54(41)$ & $0(3)$ \\
Dwarka & 30 & 1485 & $0.14(14)$ & $0.59(60)$ & $0.73(26)$ \\
(Dec 2007-Jan 2008) & 15 & 1483 & $0.24(5)$ & $0.56(75)$ & $0.76(20)$ \\
\hline
\end{tabular}

Table 4. Distribution of young, mature and old swells along the west coast of India.

\begin{tabular}{lrrrr}
\hline Location & $\begin{array}{r}\text { Water depth } \\
(\mathrm{m})\end{array}$ & $\begin{array}{r}\text { Young swell } \\
(\%)\end{array}$ & $\begin{array}{r}\text { Mature swell } \\
(\%)\end{array}$ & $\begin{array}{r}\text { Old swell } \\
(\%)\end{array}$ \\
\hline Goa & 25 & 6.05 & 92.01 & 1.94 \\
(May 2005) & 15 & 1.53 & 90.94 & 7.53 \\
Ratnagiri & 35 & 39.7 & 30.31 & 29.99 \\
(Jan-Feb 2008) & 15 & 29.42 & 32.57 & 38.01 \\
Dwarka & 30 & 8.48 & 38.73 & 52.79 \\
(Dec 2007-Jan 2008) & 15 & 0 & 12.61 & 87.39 \\
\hline
\end{tabular}

Off Dwarka, the directional spectrum and spread are totally different for the post monsoon season (Fig. 7a) compared to the pre-monsoon season at the other two locations. We can observe two distinct swell peaks from S/SSW direction and two wind sea peaks from NW/NE directions in the wave spectrum (Fig. 7a). When the winds are from NW and they are weak, NE wind seas decay with gradual increase in angular spread (Fig. 7b). However, when the winds shift to the $\mathrm{NE}$ direction and the speed increases to $3 \mathrm{~m} \mathrm{~s}^{-1}$, NE wind seas grow with minimal spread (Fig. 7c). As the NE wind sea reaches the maximum, it interacts with the wave systems: NW wind sea and S swell. The absorption from NE wind sea and S swell energy produces an overshoot in the energy density of NW wind sea with minimum spread (Fig. 7d). The interaction between the two systems results in the integration of most of the swell and NE wind sea energy into the old wind sea. Later, wind shifts to NE direction and the peak NW wind sea starts dissipating and imparting its energy to swells and $\mathrm{NE}$ wind seas. At later stages, NE wind seas disappear and the multi-directional spectrum reduces to a bimodal spectrum (Fig. 7e). Swells dominate with minimal angular spread and wind seas dissipate with high angular spread. Further, the wind sea energy is absorbed by the prevailing swells with the transformation of bimodal to unimodal wave spectrum (Fig. 7f).

\subsection{Swell age}

An investigation has been carried out to identify the various types of swells prevailing in the Arabian Sea during non-monsoon season. The analysis of swells present along the west coast of India indicates that mature swells are predominant $(92 \%$ and $91 \%$ at $25 \mathrm{~m}$ and $15 \mathrm{~m}$ depths, respectively, off Goa) due to the onset of monsoon during late premonsoon season (Table 4). The dominance of young, mature and old swells are nearly the same, varying between $30 \%$ and $40 \%$ during early pre-monsoon season (JanuaryFebruary 2008). Most of the swells in the Arabian Sea are from SW, whereas, due to the shamal event swells occur in the Persian Gulf in the NW direction. However, old swells (53\% and $88 \%$ at $30 \mathrm{~m}$ and $15 \mathrm{~m}$ depths, respectively, off Dwarka) and mature swells (39\% and $13 \%$ at $30 \mathrm{~m}$ and $15 \mathrm{~m}$ depths, respectively, off Dwarka) are predominant during post-monsoon season (December 2007-January 2008). It is also observed that the SW/SSW swells generated in the Southern Ocean during pre-monsoon and post-monsoon season are old swells, SW swells generated in the south Arabian Sea during SW monsoon (or late pre-monsoon season) are mature swells and NW swells generated (during early premonsoon season) in the north Arabian Sea are young and mature swells.

\subsection{Fetch analysis}

As fetch also plays a significant role in wave growth, we used the Kahma equation (1981) for the estimation of fetch for wind sea generation. AWS was not able to capture offshore winds, as it is installed away from the buoy (on the land). Hence, we have used IFREMER blended wind data $\left(0.25^{\circ} \times 0.25^{\circ}\right)$, available every $6 \mathrm{~h}$, to calculate the offshore extent of the wind sea fetch along the west coast of India. Fetch was obtained using Kahma equation (1981) for the Goa, Ratnagiri and Dwarka coastal regions. Figure 8 shows the minimum fetch available for the wind sea generation along the west coast of India. Aparna et al. (2005) observed that the maximum offshore extension of the sea breeze along the southwest coast of India can reach up to $180 \mathrm{~km}$. The fetch available for the development of wind seas is minimum during early post-monsoon season, and therefore, shows the presence of swell dominance. Observations also support the growth of wind seas during early pre-monsoon season. The 

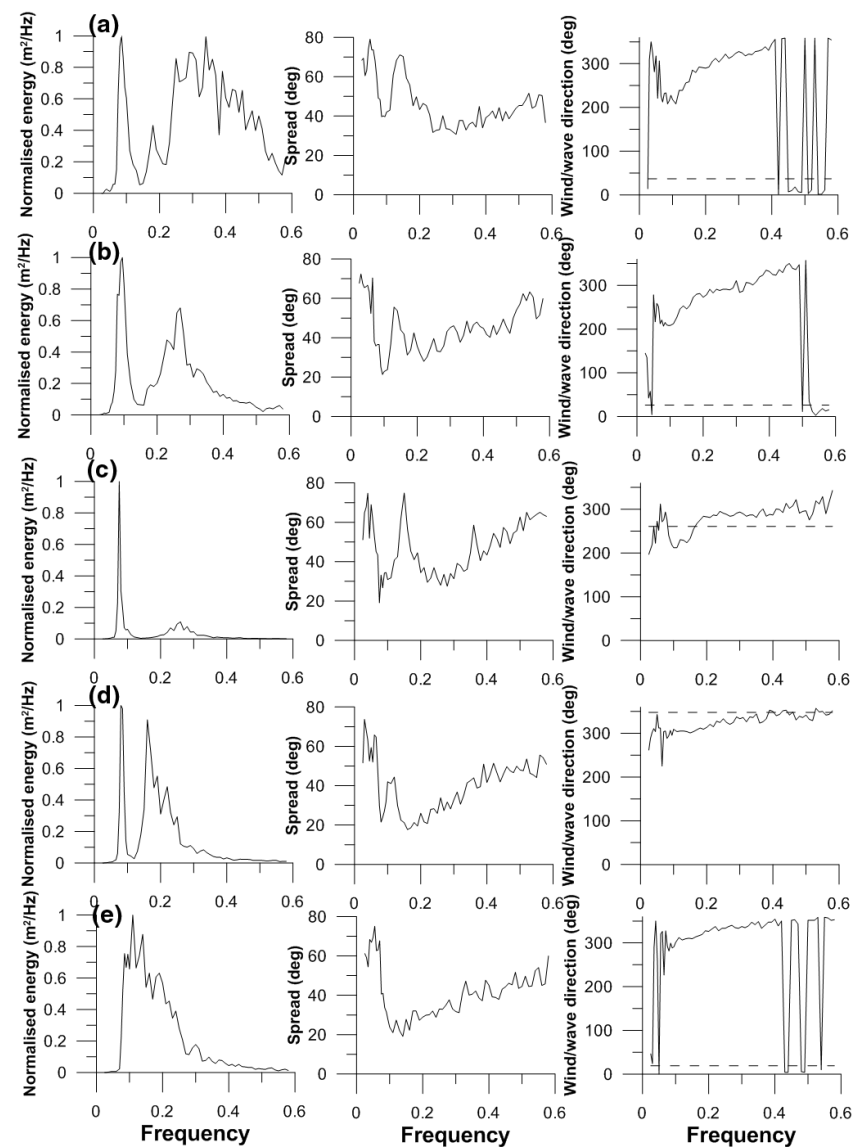

Fig. 6. Wave energy spectrum, wave spread and mean wave direction (solid line) and wind direction (dashed line) at (a) 00:00 h, (b) 06:00 h, (c) 14:00 h, (d) 19:00 h and (e) 23:00 h, respectively, off Ratnagiri during 3 February 2008.

fetch increases when winds are NW, however decreases when winds are $\mathrm{NE}$ (as the wave measurement location is very near to coast and no fetch is available in this direction). Off Goa, fetch observed for wind sea evolution was about $80 \mathrm{~km}$. It increases and reaches the maximum at every $4 \mathrm{~h}$; off Ratnagiri, fetch is about $120 \mathrm{~km}$; it increases and reaches the maximum during the shamal event; off Dwarka, when the predominant winds are NE, fetch is minimum, as there is no fetch available in this direction. Fetch increases, as the wind direction changes to NW.

During non-monsoon season, the waves generated by the local winds are fetch limited. The relation has been obtained for non-dimensional formulas relating the significant wave height, dominant wave period and wind speed parameters. To derive a non-dimensional empirical relation, logarithmic values of the non-dimensional significant wind sea height $H_{\mathrm{S}}^{*}$ and peak wind sea period $T_{\mathrm{P}}^{*}$ have been calculated (Fig. 9). The best fit between $\log \left(H_{\mathrm{Sws}}^{*}\right)$ and $\log \left(T_{\mathrm{Pws}}^{*}\right)$ has been estimated and resolved as follows:
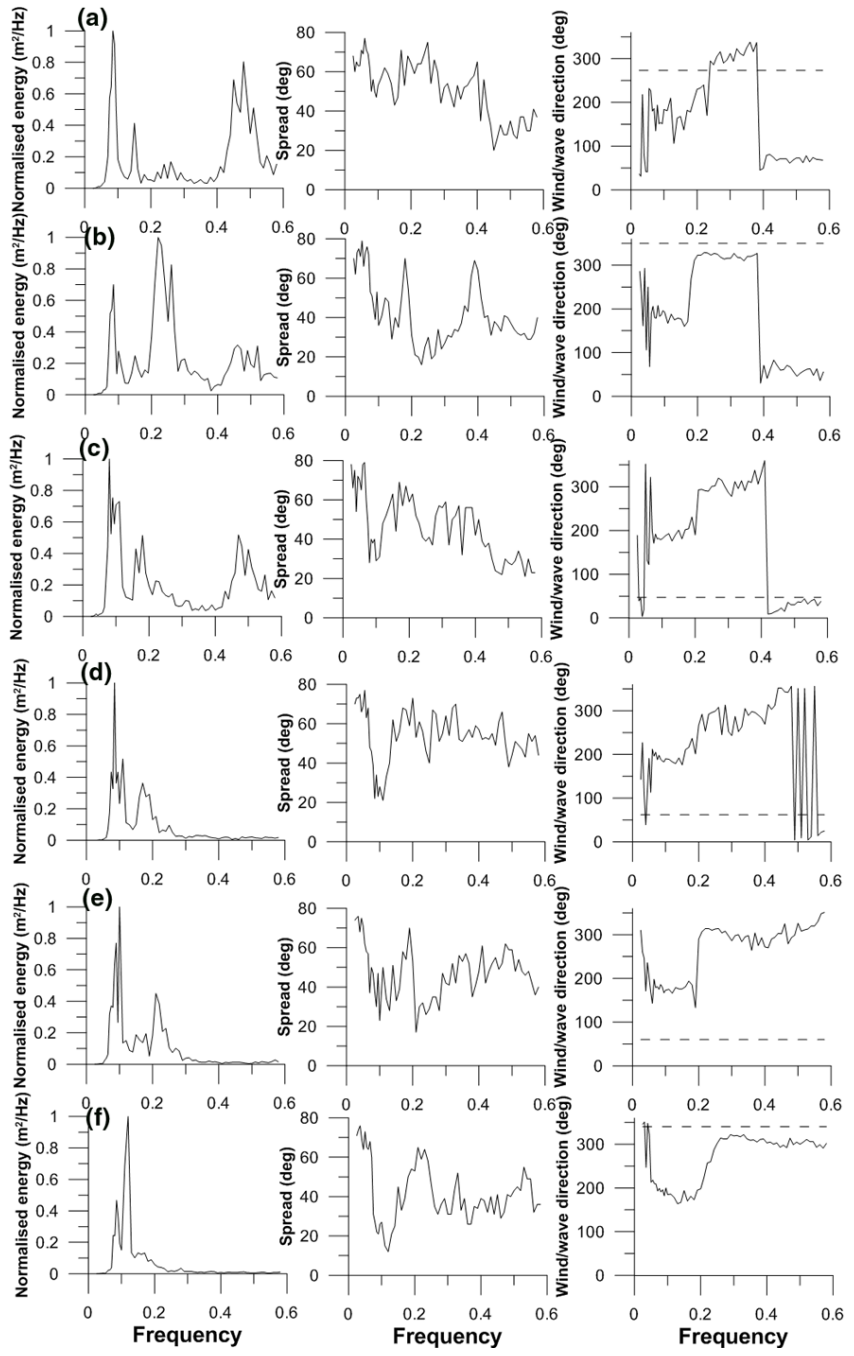

Fig. 7. (a), (b), (c), (d), (e) and (f) are wave energy spectrum, wave spread and mean wave direction (solid line) and wind direction (dashed line) at (a) 00:00 h, (b) 06:00 h, (c) 11:00 h, (d) 13:00 h, (e) 17:00 h and (f) 23:00 h, respectively, off Dwarka during 22 December 2007.

$\frac{g H_{\mathrm{Sws}}}{U^{2}}=0.0085 *\left(\frac{g T_{\mathrm{Pws}}}{U}\right)^{1.515}$.

The Eq. (2) is very close to the empirical relation derived by Wen et al. (1989). The multivariate fit gives the standard deviation of $\pm 0.04, \pm 0.032$ and \pm 0.035 w.r.t. the exponent (1.515) of the non-dimensional term in the right hand side of Eq. (2) for Goa, Ratnagiri and Dwarka region, respectively. In general, the superimposition between locally generated wind sea and swell will alter the sea state. The above equation is found to be satisfied in all the locations (Goa, Ratnagiri and Dwarka) and can be used for fetch-limited condition along the west coast of India. 

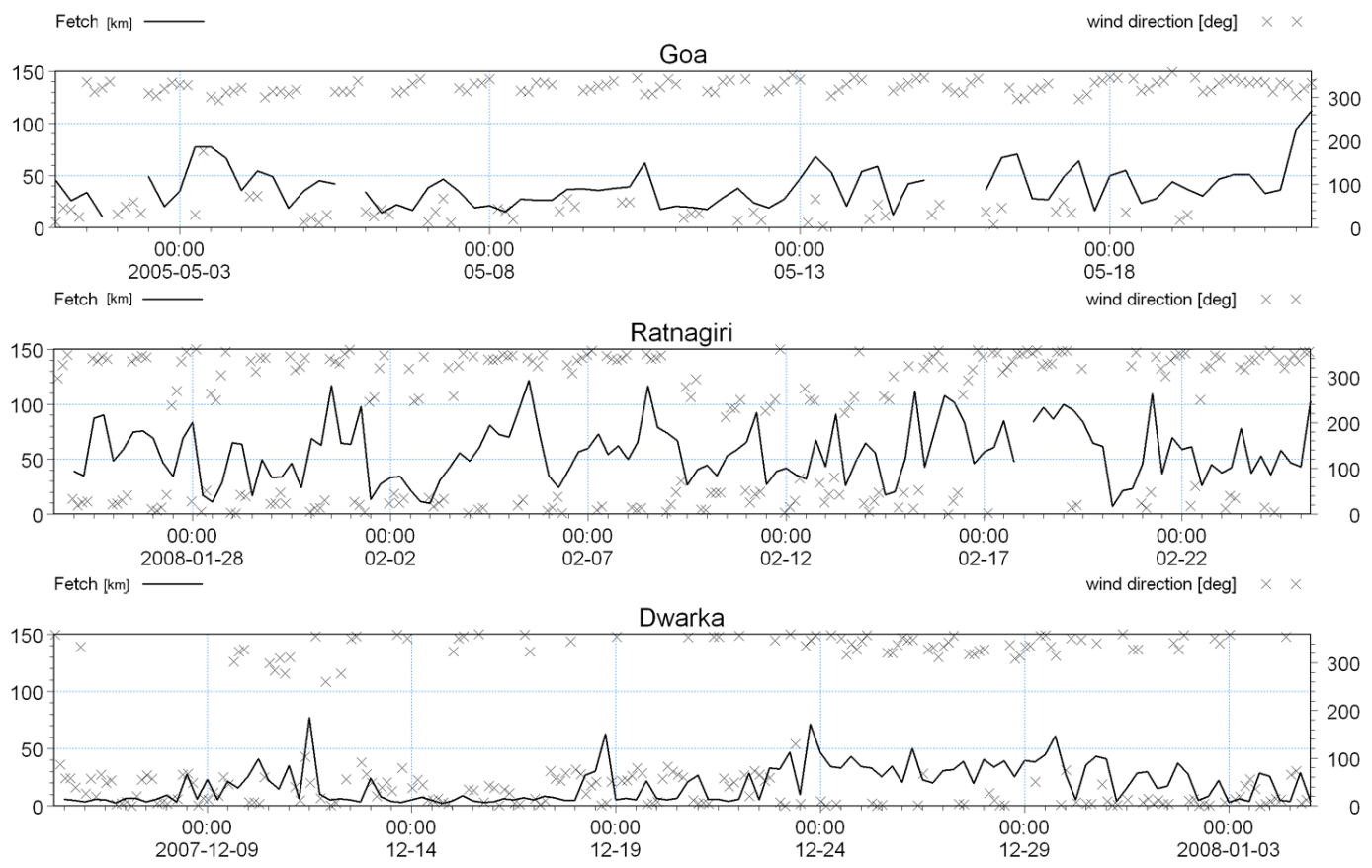

Fig. 8. Fetch and wind direction off Goa, Ratnagiri and Dwarka along the west coast of India.

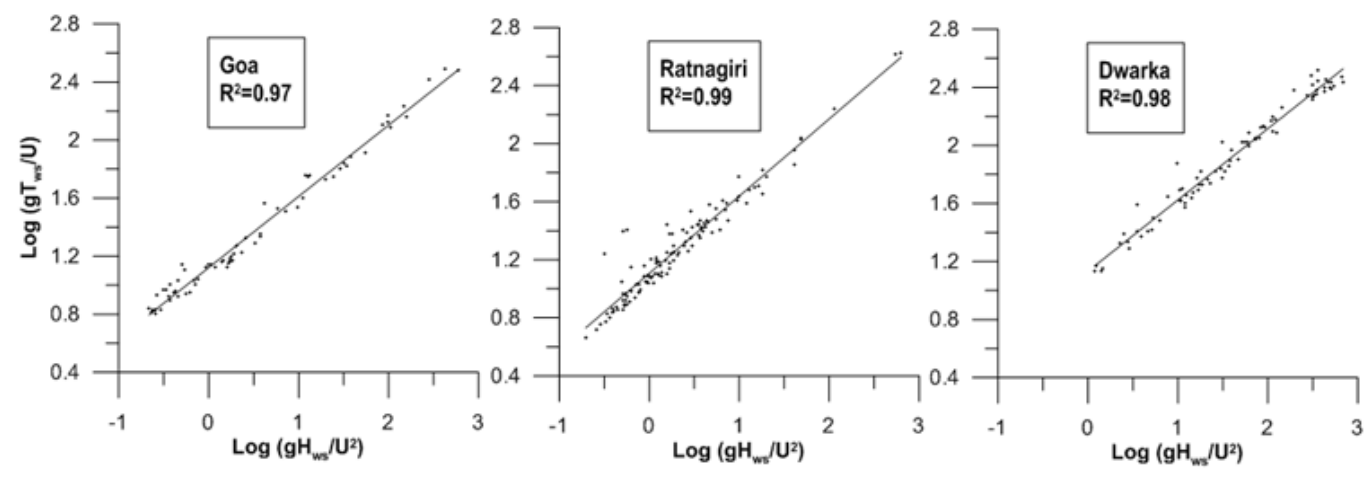

Fig. 9. Scatter between $\log \left(\mathrm{gH}_{\mathrm{Sws}} / U^{2}\right)$ and $\log \left(\mathrm{gT}_{\mathrm{Pws}} / U\right)$ at different locations along the west coast of India.

\section{Conclusions}

Measured waves collected in different years along the west coast of India show distinct variations in the wave parameters due to the co-existence of wind seas with pre-existing swells during non-monsoon season (pre-monsoon and postmonsoon seasons) which is fairly a calm weather season along these regions. The diurnal patterns observed in wind speed, wave height and wave period are very typical for the west coast of India during pre-monsoon season, due to the interaction of multidirectional wind seas of varying magnitudes in the frequency domain with co-existence of swells. We do not find systematic diurnal variability both in wave height and wave period during post-monsoon and early premonsoon seasons. SSER classifications bring out salient fea- tures of different wave systems present along the central west coast and northwest coast of India during non-monsoon season. Swells are predominant $(61 \%)$ along the northwest coast of India (off Dwarka) during post-monsoon season, and wind seas are predominant (48\%) during late post-monsoon and early pre-monsoon seasons. During late pre-monsoon season, swells (71\%) are predominant along the central west coast of India (off Ratnagiri and Goa, respectively). During most part of the non-monsoon season, the energy peaks of swell and wind sea in the spectra are moderately separated and their intermodal distance are between 0.3 and 0.7 , and those during shamal events are less than 0.3 as the energy peaks are very close to each other (unimodal).

The diurnal variations are not as significant in the post and early pre-monsoon seasons as in the late pre-monsoon 
season. Wind seas in multimodal spectrum have more minimum spreads than those with single-modal wind sea spectrum. Under low winds, the wind sea development was dominated by interactions with swell. In mixed sea states the coupling between different wave systems had a stabilizing effect of reducing a multimodal energy spectrum to a unimodal wave spectrum.

The contribution of high NW swells generated in the north Arabian Sea during late post-monsoon and early premonsoon (shamal events) seasons is very significant along the west coast of India, but otherwise the Arabian Sea is relatively calm. According to swell classification, mature swells $(91 \%)$ and old swells (88\%) are predominant during the late pre-monsoon (May) and post-monsoon (December) seasons, respectively. Young (29\%), mature (33\%) and old $(38 \%)$ swells are almost equally distributed during late postmonsoon (January) and early pre-monsoon (February) seasons along the west coast of India.

The fetch available for the evolution of wind sea spectrum off Goa and Dwarka are about $80 \mathrm{~km}$ during late premonsoon and post-monsoon periods. However, fetch increases (off Ratnagiri) and reaches about $120 \mathrm{~km}$ during pre-monsoon period.

Nevertheless, these results are only applicable for the measurements done in different years at three locations during fairly calm weather seasons and further analysis is required to confirm that these results are representative of the wave climate for non-monsoon seasons along the entire west coast of India.

Acknowledgements. We thank S. R. Shetye, Director, NIO for his constant support to this study. We acknowledge the help of our colleagues who had gone to the field and collected the oceanographic and meteorological observations. This is NIO contribution no. 5325.

Edited by: A. Sterl

\section{References}

Aboobacker, V. M., Vethamony, P., and Rashmi, R.: "Shamal" swells in the Arabian Sea and their influence along the west coast of India, Geophys. Res. Lett., 38, L03608, doi:10.1029/2010GL045736, 2011a.

Aboobacker, V. M., Rashmi, R., Vethamony, P., and Menon, H. B.: On the dominance of pre-existing swells over wind seas along the west coast of India, Cont. Shelf Res., 31, 1701-1712, $2011 \mathrm{~b}$.

Alves, J. H. G. M: Numerical modeling of ocean swell contributions to the global wind-wave climate, Ocean Model., 11, 98$122,2006$.

Aparna, M., Shetye, S. R., Shankar, D., Shenoi, S. S. C., Mehra, P., and Desai, R. G. P.: Estimating the seaward extent of sea breeze from QuikSCAT scatterometry, Geophys. Res. Lett., 32, L13601, doi:10.1029/2005GL023107, 2005.

Ardhuin, F., Herbers, T. H. C., Watts, K. P., Van Vledder, G. P., Jensen, R., and Graber, H.: Swell and slanting fetch effects on wind wave growth, J. Phys. Oceanogr., 37, 908-931, 2007.
Bentamy, A., Ayina, H.-L., Queffeulou, P., Croize-Fillon, D., and Kerbaol, V.: Improved near real time surface wind resolution over the Mediterranean Sea, Ocean Sci., 3, 259-271, doi:10.5194/os3-259-2007, 2007.

Datawell, B. V.: Datawell wave rider reference manual, Datawell BB, Zumerlustraat 4, 2012 LM Haarlem, the Netherlands, 2006.

Donelan, M. A., J. Hamilton, and Hui, W. H.: Directional spectra of wind-generated waves, Phil. Trans. Roy. Soc. London, 315, 509-562, 1985.

Gerling, T. W.: Partitioning sequences and arrays of directional ocean wave spectra into component wave systems, J. Atmos. Oc. Technol., 9, 444-458, 1992.

Gilhousen, D. B. and Hervey, R.: Improved Estimates of Swell from Moored Buoys. Proceedings of the Fourth International Symposium WAVES 2001, ASCE: Alexandria, VA, 387-393, 2001.

Guedes Soares, C.: Representation of double-peaked sea wave spectra, Ocean Eng., 11, 185-207, 1984.

Guedes Soares, C.: On the occurrence of double peaked wave spectra, Ocean Eng., 18, 167-171, 1991.

Hanson, J. L. and Phillips, O. M.: Automated analysis of ocean surface directional wave spectra, J. Atmos. Oc. Technol., 18, 277293, 2001.

Harish, C. M. and Baba, M.: On spectral and statistical characteristics of shallow water waves, Ocean Eng., 13, 239-248, 1986.

Holthuijsen, L. H.: Observations of the directional distribution of ocean wave energy, J. Phys. Oceanogr., 13, 191-207, 1983.

Kahma, K. K.: A study of the growth of the wave spectrum with fetch, J. Phys. Oceanogr., 11, 1503-1515, 1981.

Kumar, V. S., Anand, N. M., Kumar, K. A., and Mandal, S.: Multipeakedness and groupiness of shallow water waves along Indian coast, J. Coastl. Res., 19, 1052-1065, 2003.

Neetu, S., Shetye, S., and Chandramohan, P.: Impact of sea-breeze on wind seas off Goa, west coast of India, J. Earth Sys. Sci., 115, 229-234, 2006.

Peterson, E. W. and Hennessey Jr., J. P.: On the use of power laws for estimates of wind power potential, J. Appl. Met., 17, 390394, 1978.

Portilla, J., Francisco, J. O., and Monbaliu, J.: Spectral partitioning and identification of wind sea and swell, J. Atmos. Oc. Technol., 26, 107-122, 2009.

Rodriguez, G. R. and Guedes Soares, C.,: The Bivariate distribution of wave heights and periods in mixed sea states, J. Offshore Mech. Arc. Eng., 121, 102-108, 1999.

Sanil Kumar, V., Ashok Kumar, K., Pednekar, P., and Gowthaman, R.: Sea and swell along west coast of India: Study based on measured data, Fourth Indian National Conference on Harbour and Ocean Engineering 12-14 December 2007, at NITK, Surathkal, 2007.

Semedo, A., Suselj, K., Rugersson, A., and Sterl, A.: A global view on the wind sea and swell climate and variability from ERA-40, J. Clim., 24, 1461-1479, 2011.

Thompson, W. C., Nelson, A. R., and Sedivy, D. G.: Wave group anatomy. Proceedings of 19th conference on Coastal Engineering, Vol. I, American Societ of Civil Engineers, 661-677, 1984.

Vethamony, P. and Sastry, J. S.,: On the characteristics of multipeaked spectra of ocean surface wave, J. Inst. Eng. India., 66, 129-132, 1986.

Vethamony, P., Aboobacker, V. M., Sudheesh. K., Babu, M. T., and Ashok Kumar, K.: Demarcation of inland vessels limit off Mor- 
mugao port region, India: a pilot study for the safety of inland vessels using wave modeling, Nat. Hazards, 49, 411-420, 2009. Vethamony, P., Aboobacker, V. M., Menon, H. B., Ashok Kumar, K., and Cavaleri, L.: Superimposition of wind seas on preexisting swells off Goa coast, J. Mar. Syst., 87, 47-54, 2011.
Wang, D. W. and Hwang, P. A.: An operational method for separating wind sea and swell from ocean wave spectra, J. Atmos. Oc. Technol., 18, 2052-2062, 2001.

Wen, S. C., Zhang, D. C., Guo, P. Z., and Chen, B. H.,: Parameters in wind-wave frequency spectra and their bearings on spectrum forms and growth, Ac. Oceanol. Sin., 8, 15-39, 1989. 